\title{
Sustentabilidade nas instituições financeiras públicas e privadas: percepção, atitude e comportamento dos colaboradores
}

\section{Juliana Jorge do Prado ${ }^{1}$, Alcido Elenor Wander ${ }^{1}$ e Bento Alves da Costa Filho}

\author{
${ }^{1}$ Centro Universitário Alves Faria. Av. Perimetral Norte, 4129. Vila João Vaz. \\ Goiânia-GO, Brasil (CEP 74445-190). \\ ${ }^{2}$ Centro Universitário Alves Faria. QRSW 2, Bloco B4, Apto 103. Brasília-DF, Brasil \\ (CEP 70675-224). E-mail: costaf@uol.com.br.
}

Resumo. Decorrente da realidade ecológica e de empresas cada vez mais competitivas, surge na atualidade, um diferencial notável nas organizações: a responsabilidade socioambiental. A implantação de programas com esse cunho dentro das empresas está condicionada a uma gama de fatores para lograr êxito, como programas adequados, contextualizados e bem instituídos, incluindo mensuração de resultados, envolvimento dos colaboradores, dentre outros. Na busca por uma perspectiva melhor para o futuro, surge o interesse pelo estudo do comportamento e da percepção apresentados por funcionários de diferentes instituições bancárias frente ao desenvolvimento sustentável, diante das políticas já instituídas nas empresas. Este processo foi realizado por meio de um estudo exploratório tipo survey, comparando-se instituições financeiras públicas e privadas. Os resultados apontam para uma melhor percepção por parte dos empregados de instituições privadas, com maior predisposição para uma conduta ecologicamente correta no ambiente institucional e comportamentos mais próximos do objetivo das políticas implantadas. Embora os colaboradores tenham apresentado certo grau de conhecimento, predisposição favorável e comportamentos consistentes em prol do meio ambiente, identificou-se que há espaço para um maior envolvimento destes no desenvolvimento de ações proativas nas instituições.

Palavras-chaves: Conduta ecológica; Responsabilidade socioambiental; Desenvolvimento sustentável.

Abstract. Sustainability in public and private financial institutions: employees' perception, attitudes and behavior. As a result of the ecological reality and increasingly competitive companies, there is a notable difference in organizations: socioenvironmental responsibility. The implementation of such programs within companies is conditioned by a range of factors for success, such as adequate, contextualized and well-established
Recebido

$20 / 09 / 2019$

Aceito

$27 / 12 / 2019$

Publicado

$31 / 12 / 2019$

Acesso aberto

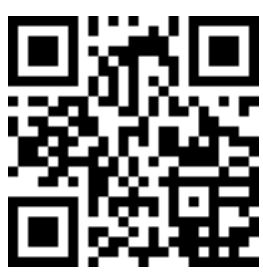

ORCID

(ㄱ) 0000-0002-8658-0637 Juliana Jorge do Prado

D 0000-0001-9656-8773 Alcido Elenor Wander

D 0000-0002-3739-5320

Bento Alves da Costa Filho 
programs; measurement of results; involvement of employees, among others. In the search for a better perspective for the future, there is interest in the study of the behavior and perception presented by employees of different banking institutions towards sustainable development, in view of the policies already instituted in companies. This process was carried out through an exploratory survey study, being carried out a comparison between public and private financial institutions. The results point to a better perception on the part of the employees of private institutions, with a greater propensity for an ecologically correct behavior in the institutional environment and behaviors closer to the goal of the implemented policies. Although the employees have presented a certain level of knowledge, favorable attitudes and consistent pro environment behavior, there is still room for a greater involvement in the developing of proactive ecological actions in the institutions.

Keywords: Ecological behavior; Socio-environmental responsibility; Sustainable development.

\section{Introdução}

0 progresso tecnológico em diferentes áreas contribuiu muito para o bem-estar da sociedade, a qual por sua vez apresentou um grande crescimento demográfico nas últimas décadas. Porém, esse desenvolvimento agregado ao crêscimento populacional tem comprometido a qualidade de vida das pessoas, com probabilidade de agravamento num futuro próximo.

Desse modo, no cenário organizacional, um dos diferenciais de competitividade adotados pelas empresas é o desempenho ambiental. Produzir, gerar lucros, sem que o meio ambiente seja prejudicado, pode causar percepções positivas de consumidores. Contudo, apesar da mudança comportamental existente, o que se observa dentro das instituições financeiras é a utilização de critérios ambientais para a concessão de crédito, mas nem sempre para a conduta interna do banco.

Ocorre, desta forma, pouco empenho nas políticas sustentáveis para o público interno dos bancos, o que por sua vez, ocasiona maior descaso por parte dos colaboradores no aspecto da preservação ambiental. E, mesmo com a implantação dessas políticas, há ainda a

dificuldade de absorção destas pelos seus empregados. Nesse contexto, emerge o presente estudo, voltado para a análise do comportamento apresentado pelos funcionários de instituições financeiras diante de projetos ambientais e suas percepções quanto ao posicionamento da instituição frente à responsabilidade social empresarial (RSE).

A sustentabilidade ambiental ganhou destaque frente à urgência existente na mudança do comportamento social em busca de melhores condições de vida para a população. Diversos efeitos, resultantes da conduta humana inconsequente, são fortemente percebidos atualmente.

Essa conduta se deu por um longo período, mas esteve mais presente na sociedade industrial, onde "a ideia de produção de riquezas dominava a ideia de produção de riscos, e estes, apesar de se concretizarem regularmente em danos efetivos, não se anunciavam de modo suficientemente forte a ponto de subverter a lógica do sistema" (Campos e Ardisson, 2012, p. 95).

Porém, com o passar do tempo, esses danos enfim se tornaram mais perceptíveis pela sociedade. Ao observar e monitorar tais resultados percebe-se que houve um comportamento omisso na 
corrida desregrada pelo progresso. "A destruição então inerente à produção já não podia escapar aos olhos atentos de uma sociedade permanentemente alerta" (Campos e Ardisson, 2012, p. 93).

Este estado alerta trouxe consigo a transformação na consciência coletiva dos indivíduos, ampliando a responsabilidade das organizações com aspectos que historicamente nunca lhes foram cobradas. Essa transformação modificou ainda o poder de influência na formação do subconsciente coletivo (Kelm et al., 2014, p. 404).

Partindo desse pressuposto, a Comissão Mundial sobre o Meio Ambiente e Desenvolvimento (CMMAD, 1991, p. 46), defendeu o progresso aliado à manutenção do ecossistema, nomeando-o como desenvolvimento sustentável: "aquele que atende as necessidades do presente sem comprometer a possibilidade de as gerações futuras atenderem a suas próprias necessidades".

Entretanto, a existência de dificuldade no desenvolvimento sustentável não se limita à aplicação, mas também ao entendimento, ou à "existência de múltiplos entendimentos do conceito em si" (Rufino et al., 2014, p. 7). Presume-se que a sustentabilidade apresenta interpretações positivas, quando relacionada com estratégias que reforçam um modelo de melhoria nos padrões de crescimento econômico em harmonia com o meio ambiente; e negativa quando retrata "a estratégia falaciosa para a manutenção da lógica dominante do mercado capitalista e do consumo centrado no crescimento econômico" (Silva e Lopes, 2014, p. 79).

Como o ser humano é a força motriz que move a engrenagem da preservação ambiental, "pouco adiantará tecnologias de controle ambiental de última geração se as pessoas não redefinirem 0 seu comportamento quanto ao consumo e ao uso desordenado dos recursos naturais" (Medeiros et al., 2015). Isso porque, os "indivíduos são responsáveis pelas escolhas que fazem ao longo do trajeto, bem como com os efeitos benéficos e maléficos de suas ações" (Silva e Lopes, 2014, p. 89).

\section{Responsabilidade socioambiental}

"A degradação de ambiente está colocando as organizações diante do desafio e da necessidade de redefinirem suas prioridades e seus valores" (Medeiros et al., 2015). Essa necessidade de mudança no cenário empresarial se dá como consequência da compreensão do poder de mercado que a sociedade exerce sobre as organizações, tornandose assim uma pressão social sobre estas, para a adoção de práticas responsáveis socialmente (Feitosa et al., 2014, p. 15). Desta pressão exercida, surge a Responsabilidade Social Empresarial (RSE), também conhecida como Responsabilidade Social Corporativa (RSC) ou Responsabilidade Social Ambiental (RSA).

Tais práticas têm sido utilizadas pelas organizações como uma forma de se comprometer com a sociedade local, assumindo ações e consequências destas. Esse compromisso, melhora sua imagem e torna-se uma vantagem competitiva para as mesmas.

A gestão ambiental nas organizações surge como um instrumento capaz de identificar os principais impactos ambientais causados por suas atividades, permitindo a adoção de uma política de controle com ações que visem mitigá-los, a fim de compatibilizar crescimento econômico e preservação ambiental (Garcia et al., 2007; Medeiros et al., 2015).

No entanto, há algumas resistências no processo visto que, o "discurso e a prática da responsabilidade socioambiental surgem num contexto em que as empresas detinham liberdade total para agir, com algumas restrições no interior de suas fronteiras" (Bagnolo, 2010, p. 411).

Entretanto, essa perspectiva não deve estabelecer na nova rotina limitação da gestão ambiental à prevenção e 
recuperação ambiental. Feitosa et al. (2014, p. 15), orientam que "além das questões ambientais, deve-se considerar a RSE, envolvendo a atenção e cuidado com funcionários e fornecedores, a transparência na comunicação e nas formas de marketing utilizadas e a ética nas relações com a sociedade".

Com as ações de responsabilidade socioambiental contribuindo positivamente para o desenvolvimento empresarial, surge "uma nova consciência para o mundo dos negócios, amenizando (e não solucionando, é importante frisar) os efeitos nocivos do modo de produção capitalista" (Bagnolo, 2010, p. 411).

Suas conceituações e definições vão variar de acordo com o contexto em que são formuladas e em função dos interesses e da posição ocupada no espaço social pelos seus formuladores (Cruvinel, 2008; Véras, 2009). Concomitantemente, algumas "iniciativas podem apresentar custos significativos que não necessariamente se traduzem em melhoria socioambiental para as comunidades afetadas pelas atividades da empresa" (Garcia et al., 2007, p. 535).

Com a formação de novos padrões nas organizações, decorrente de normatização social onde o agente indutor desse novo padrão não é a organização, surge a perda do caráter estratégico competitivo daquela conduta, na perspectiva do mercado. A esse comportamento passa-se a atribuir exclusivamente o seu cumprimento legal (Kelm et al., 2014, p. 410).

Como marco dessa grande transformação ocorrida nesse campo, surge dentro das normas e regulamentações ambientais a Constituição de 1988. Ela prevê em seu artigo 225, que todos têm direito ao meio ambiente ecologicamente equilibrado, bem de uso comum do povo e essencial à sadia qualidade de vida, impondo-se ao Poder Público e à coletividade o dever de defendê-lo e preservá-lo para as presentes e futuras gerações (Brasil, 1988). Porém, é importante ressaltar que "se o meio ambiente sadio é um direito ele é também um dever, que compete a toda a sociedade" (Agenda 21, 1995, p. 8).

Mas, às avessas das obrigações de cada indivíduo, encontra-se o próprio individualismo, onde apesar de os consumidores terem noção do que é Responsabilidade Social, por demonstrarem que estão informados a esse respeito, observa-se que apenas uma parcela destes estaria disposta a pagar mais por produtos ecológicos (Tamashiro et al., 2012, p. 208).

\begin{abstract}
Apesar do aumento da consciência e do interesse do consumidor por produtos verdes e de uma prédisposição para compra de produtos e serviços mais ecologicamente corretos, pode-se notar muitas vezes a falta de correspondência nos consumidores entre sua atitude e suas ações [...] (Vaccari et al., 2016, p. 44).
\end{abstract}

0 consumidor brasileiro, por exemplo, valoriza mais o desempenho do composto mercadológico do que o desempenho ambiental do produto (Santos e Porto, 2014, p. 616). Ainda assim, apesar da contradição consumidora, é fato a existência de uma busca incessante por vantagens competitivas no aspecto ambiental dentro das organizações, alimentando a necessidade não apenas de atuação, mas de uma ampla divulgação desses feitos, para que a construção dessa imagem seja sólida.

Origina-se assim, o chamado marketing verde, que busca "estimular estratégias e posturas verdadeiras e éticas, que busque uma visão sempre crítica e consciente em todas as dimensões da sustentabilidade, ultrapassando velhos paradigmas de manipulação do mercado e falácias organizacionais" (Silva e Lopes, 2014, p. 88).

Nesta perspectiva, a possibilidade de enquadramento estratégico de uma iniciativa socioambiental é o seu caráter de legitimação social, ou seja, de gerar uma percepção positiva, não de um 
produto, mas da marca como um todo (Kelm et al., 2014, p. 411). Assim, não se pode olhar a prática socioambiental apenas como um elemento de proteção. Ela atua como um indicador de qualidade para os consumidores.

Os bancos por sua vez, enxergam na responsabilidade socioambiental uma maneira de dar visibilidade à empresa, agregando valor à marca. É uma forma de melhorar a credibilidade da instituição e sua reputação diante dos investidores, clientes e sociedade, atuando como um marketing social. 0 intuito maior da instituição financeira seria o de vender sua imagem, pois, como qualquer empresa, não abre mão do esforço de maximizar seus lucros em um setor extremamente competitivo (Braga e Moura, 2015).

Essa nova ferramenta disponível aos bancos, o marketing social, torna-se uma opção baseada no resultado projetado por atender os anseios ambientais de uma comunidade. 0 reconhecimento advindo seria explicado a partir da certificação de que as necessidades, desejos e expectativas em relação ao meio ambiente poderiam ser preenchidos pelo esforço ambiental de uma instituição financeira, onde se espera que o cliente avalie positivamente o relacionamento, manifestando maior satisfação (Santos e Porto, 2014, p. 608).

\footnotetext{
Por ora, não se pode esperar que a percepção da postura ambiental venha a encorajar o principal critério de decisão para início, aumento ou encerramento de um relacionamento bancário. Há aspectos contingenciais e mercadológicos que concorrem para subsidiar aquelas decisões (Santos e Porto, 2014, p. 615).
}

Entretanto, tudo aquilo que é externado pelas organizações como uma postura socialmente responsável ambientalmente, pode ser compreendido sistematicamente como uma ação social estratégica. As estratégias têm um princípio claramente econômico e competitivo, voltadas para a busca de melhores níveis de posicionamento, seja como fator de diferenciação, seja como elemento legitimador junto ao mercado (Kelm et al., 2014, p. 413).

Contudo, apesar do esforço realizado por inúmeras empresas em apresentarem relatórios e propagandas com iniciativas que visem à sustentabilidade, isso "nem sempre condiz com as ações que elas desenvolvem internamente, ainda há um imenso desafio para incorporá-lo no universo empresarial" (Ipiranga et al., 2011, p. 14). Esse processo é relatado por Silva e Lopes (2014, p. 82) como Greenwashing. "Um termo em inglês que significa 'lavagem verde', faz referência a algo que quer transmitir uma imagem de ecologicamente correto, quando na verdade não é."

As exigências da sociedade no que tange ao setor bancário, não são tão perceptíveis quanto em outros setores (Feitosa et al., 2014, p. 15). Essa lacuna existente resulta da inserção dos bancos em um contexto diferenciado das demais organizações, o que não promove grande notoriedade quando da realização de práticas sustentáveis em sua rotina. Mas, "embora a atividade financeira não seja de grande impacto ambiental, os próprios bancos, em pequena medida, são também poluidores" (Blank e Brauner, 2009, p. 274).

Contrariando essa perspectiva de baixo impacto ambiental, Feitosa et al. (2014, p. 17) declaram que "a quantidade de recursos consumidos pelos bancos (papel e energia) e a geração de resíduos merecem destaque".

\section{Da percepção ao comportamento}

Diante dos acontecimentos cotidianos, cada indivíduo, com base em sua carga emocional, projeta sua percepção acerca dos fatos. São interpretações apresentadas em relação a fatores exteriores, de forma intangível, podendo ser compartilhados e/ou similares em um determinado grupo, seja ele grande ou pequeno, desde que 
possuam afinidades entre si. "A percepção é entendida como o caminho complexo de se obter informação acerca do mundo que nos rodeia, através dos nossos sentidos para, posteriormente, se apreender essa informação na consciência" (Santos e Souza, 2015, p. 59).

Para Brandalise e Bertolini (2013, p. 28), "percepção é a interpretação que as pessoas fazem de uma mensagem a partir da interação dos estímulos internos e externos, que podem ser diferentes dependendo do indivíduo".

Em decorrência dos desequilíbrios ambientais causados e da criação de novas necessidades advindas, "o ser humano está se tornando cada vez mais reflexivo e atuante em relação à responsabilidade social e ambiental" (Rodrigues et al., 2014, p. 317). Porém, é importante salientar a distância existente entre a reflexão e a atuação do indivíduo, mesmo quando se refere à conservação ambiental do planeta. Dentro das organizações, Parente et al. (2013, p. 4) asseguram que "pesquisas recentes no Brasil apontam que os colaboradores pouco participam dos programas de RSC, o que faz com que eles não reconheçam as ações das empresas onde trabalham e nem se comprometam e se engajem nos projetos de RSC".

Já em uma perspectiva mais otimista, acredita-se que a organização possui a capacidade de transmitir valores de forma a alterar o comportamento destes, com vistas à sustentabilidade do meio ambiente.

0 fenômeno sustentabilidade, por ainda ser uma ação da esfera cultural, pressupõe a importância da transmissão de valores sustentáveis pela empresa aos seus colaboradores a fim de que estes venham a adotar ações e atitudes sistemáticas de ordem ecológica e sustentável no âmbito empresarial e por consequência reproduzirem em seu ambiente familiar e de convívio social. Tornando-se desta maneira passível de traduzir-se em um dado estatístico de valores (Beuron et al., 2014, p. 182).

Todavia, há que se compreender o intuito e a abrangência dos modelos ambientais instituídos. Alguns autores questionam se essas ações de RSC,

São concebidas e executadas com algum intuito para que sejam conhecidas, reconhecidas e defendidas pelo público interno ou se é pensada como um atributo de competição externa. Por esta ótica, não seria interesse prioritário da organização fazer com que o seu público interno a reconheça como socialmente responsável, mas sim que o mercado lhe dê esta distinção (Parente et al., 2013, p. 13).

Brandalise e Bertolini (2013, p. 31) esclarecem que "a percepção ambiental, decorrente da interpretação dos estímulos externos (informações) e internos (crenças, valores), somados às influências recebidas do meio externo, se reflete nas atitudes e comportamento de aquisição e consumo". Esse ciclo é realimentado constantemente por meio da repetição/inserção desses estímulos, sendo passíveis de eventuais transformações.

Todavia, o reflexo ocasionado por parte das organizações pode apresentar determinadas particularidades, já que a "forma como a empresa atua e desenvolve suas ações sociais está relacionada com sua cultura e estratégias específicas, variando de acordo com a natureza de suas atividades" (Santos e Souza, 2013, p. 4).

Com base em suas percepções formadas, cada indivíduo constrói dentro de si, uma predisposição de reação a um determinado estímulo. Seria uma resposta provável a ser dada em determinada circunstância, o que não significa necessariamente a concretização do ato. Esse aspecto estaria mais relacionado às crenças e valores do indivíduo, sendo esta intenção de comportamento, a própria atitude. 
Silva et al. (2016, p. 61) defendem que a "atitude é uma manifestação de vontade que parte dos valores intrínsecos do indivíduo". Quanto mais acessível é uma atitude na memória, mais intensa é a força da associação objetoavaliação (Santos e Souza, 2013, p. 5). "Considerando que a atitude pode ser moldada tomando por base as experiências ou informações repassadas, as empresas com práticas de responsabilidade social podem ser impulsionadoras de mudanças de atitudes de seus colaboradores" (Santos e Souza, 2013, p. 9).

Se a atitude é a intenção de agir, o comportamento, por sua vez, está representado pela ação efetiva do indivíduo frente uma situação específica. De forma geral, ele está relacionado aos valores que contextualizam esse indivíduo. Esses valores atuam como guias seletores da conduta humana.

O valor pode ser entendido como norma ou critério, um padrão que dita quais ações devemos ou não manter. Utiliza-se o valor como justificativa para o comportamento, possibilita comparações entre o "eu" e o "outro", além de permitir julgamentos morais (Beuron et al., 2014, p. 170).

Beuron et al. (2014, p. 171) ressaltam ainda a possível existência de "conflitos entre os valores do indivíduo e da coletividade", onde tendemos a respeitar os valores individuais ante os demais.

O comportamento é determinado pela atitude, por meio da avaliação positiva ou negativa que o indivíduo faz sobre como se comportar; pelas normas subjetivas, através da pressão social percebida para desempenhar ou não o comportamento; e pelo controle percebido, que nada mais é do que a crença que o indivíduo possui sobre a facilidade ou dificuldade de desempenhar o comportamento (Santos e Souza, 2013, p. 8-9).
Apesar da premissa de que o comportamento é guiado pela atitude, Vaccari et al. (2016) ressaltam a incoerência do indivíduo, entre seu discurso e suas ações, a falta de correspondência entre suas atitudes e o seu comportamento.

Sabe-se que a consciência ambiental exerce uma determinada influencia no comportamento individual, de forma que quanto maior for o nível de consciência do indivíduo, maior deverá ser o seu grau de percepção referente à conduta ecologicamente correta (Silva et al., 2016, p. 60). Rodrigues et al. (2014) compactuam dessa perspectiva ao conceber que algumas variáveis podem interferir nas orientações atitudinais e comportamentais dos indivíduos acerca das preocupações ambientais. Fatores como idade, sexo, renda e escolaridade podem alterar a percepção e o comportamento frente à sustentabilidade ambiental.

Todavia, a incoerência existente entre a atitude e o comportamento dos indivíduos, no aspecto ambiental, pode ser evidenciada quando pessoas que afirmam serem conscientes em relação ao meio ambiente utilizam outros critérios de compra em detrimento do critério ecológico na sua decisão. Dessa forma, a predisposição ou atitude ecológica não se transforma em comportamento de compra ou ação favorável ao meio ambiente (Vaccari et al., 2016, p. 45).

Alguns autores explicam que fatores culturais, sociais, pessoais e psicológicos moldam o comportamento de maneira peculiar em cada localidade investigada, o que torna difícil propor generalizações plenas de teorias (Rodrigues et al., 2014, p. 331).

Em meio a essa ampla abrangência comportamental do indivíduo, permeada pela dicotomia, Parente et al. (2013, p. 13) constataram em sua pesquisa "que as melhores empresas para se trabalhar que possuem práticas mais consolidadas em RSC não 
necessariamente são reconhecidas como tais pelos seus empregados".

Entretanto, cientes da importância do comportamento dos colaboradores rumo ao sucesso de projetos ambientais nas empresas, diversos pesquisadores voltaram seus esforços para o levantamento de informações acerca da percepção que os mesmos têm formado sobre a Responsabilidade Social Empresarial no ambiente de trabalho.

Parente et al. (2013, p. 11) constataram ainda, em suas pesquisas que "o estágio de RSC em que a empresa se encontra, com práticas consolidadas ou não, tende a não estar relacionado com as percepções que os colaboradores possuem sobre a RSC das empresas em que trabalham".

Santos e Souza (2013, p. 13) por sua vez, observaram que "os funcionários que valorizam as práticas de RSE desenvolvem uma relação de confiança e dedicação com a empresa, favorecendo a intenção de comprometimento, podendo resultar em uma ação comportamental". (Santos; Souza, 2013, p. 1).

Nalesso et al. (2013, p. 3), conforme os dados obtidos em sua pesquisa, sugeriram que a responsabilidade ambiental é ainda pouco percebida como valor da organização pelos colaboradores, assim como a questão ambiental ainda não está consolidada na percepção dos mesmos. Observa-se ainda um nível de diferenciação entre os colaboradores, onde nota-se subculturas distintas coexistindo na organização.

Já a pesquisa realizada por Araújo et al., (2014, p. 358) constatou que a educação ambiental nas empresas "conduz os profissionais a uma mudança de comportamento e atitudes em relação ao meio ambiente interno e externo às organizações, despertando a conscientização para a ação e a busca de soluções concretas para os problemas ambientais que ocorrem".

Beuron et al. (2014) alertam que o uso de escalas de percepção pode não apresentar resultados estatísticos definitivos, uma vez que o assunto sustentabilidade ainda é algo muito novo para a maioria das pessoas, e às vezes até desinteressante, mesmo em uma empresa que possui uma imagem socioambiental reconhecida perante a sociedade.

Já os resultados obtidos por Andrade et al. (2015) em sua pesquisa, revelaram que os valores relativos ao trabalho e a satisfação no trabalho influenciam positivamente os comportamentos de cidadania organizacional, sendo os valores independentes de maior influência.

Observa-se assim, que apesar dos diferentes ambientes organizacionais e de resultados diversificados, a atenção ainda assim tem sido voltada ao público interno das organizações, não pela curiosidade em si, mas pelo valor imensurável que estes indivíduos agregam aos objetivos da empresa.

\section{Materiais e métodos}

Para atingir o objetivo proposto, foi realizado um levantamento (survey) de dados, com corte transversal, com a coleta de informações da amostra realizada uma única vez. 0 universo de estudo englobou agências de cinco grandes instituições financeiras na cidade de Goiânia (GO), sendo realizada uma amostra não probabilística por conveniência, com questionário estruturado como instrumento utilizado na coleta de dados.

A elaboração do questionário foi embasada em outros estudos envolvendo sustentabilidade socioambiental (Véras, 2009, Parente et al., 2013, Santos e Souza, 2013, Araújo et al., 2014, Feitosa et al., 2014, Silva e Lopes, 2014, Santos e Porto, 2014, Andrade et. al., 2015, Medeiros et al., 2015).

0 questionário foi estruturado em três blocos principais, abordando (1) indicadores da postura ambientalmente responsável das instituições financeiras, (2) a percepção dos colaboradores sobre esta postura, e (3) as atitudes dos 
próprios colaboradores sobre a questão ambiental. Além destes blocos, havia um grupo de questões com a finalidade de classificar o perfil demográfico dos respondentes.

Foram aplicados 71 questionários, entre os meses de fevereiro a maio do ano de 2017, a empregados efetivos, que possuíam como característica comum a atuação em instituições bancárias da cidade de Goiânia (GO).

A coleta de dados foi realizada por meio da aplicação de 71 questionários a empregados efetivos, entre os meses de fevereiro a maio do ano de 2017, em agências de cinco grandes instituições financeiras na cidade de Goiânia (GO). De um total de 69 questionários válidos, 36 foram aplicados em bancos privados e 33 foram aplicados em bancos públicos.

Nas questões com escala de Likert (1932), foi utilizada a gradação original de 1 a 5 para cada resposta obtida. Foi montado um banco de dados com o suporte do software IBM SSPS Statistics, o qual permitiu a elaboração das tabelas apresentadas.

Tendo como pressuposto implícito a concepção da existência de percepções e comportamentos diferentes entre as Instituições Públicas e Privadas, o Teste $t$ evidenciou quando as médias obtidas apresentaram diferenças significativas onde $(\mathrm{p}) \leq 0,05$. Para itens onde (p) $>0,05$, a diferença existente entre os dois tipos de Instituições é considerada não significativa.

\section{Resultados obtidos e discussão}

A análise se inicia com as características sociodemográficas dos colaboradores que responderam à pesquisa. As tabelas 1 e 2 apresentam o perfil dos respondentes separados pelo tipo de instituição, pública ou privada.

Tabela 1. Perfil geral bancos públicos.

\begin{tabular}{|c|c|c|}
\hline Sexo & Faixa Etária & Renda Familiar \\
\hline Feminino - 45,4\% & 18 a 25 anos $-6,1 \%$ & $\mathrm{R} \$ 641,00$ a $\mathrm{R} \$ 1.450,00-3 \%$ \\
\hline \multirow[t]{4}{*}{ Masculino - 54,6\% } & 26 a 35 anos $-36,4 \%$ & $\mathrm{R} \$ 1.451,00$ a $\mathrm{R} \$ 2.410,00-3 \%$ \\
\hline & 36 a 45 anos $-18,2 \%$ & $\mathrm{R} \$ 2.411,00$ a $\mathrm{R} \$ 4.430,00-18,2 \%$ \\
\hline & 46 a 55 anos $-24,2 \%$ & $\mathrm{R} \$ 4.431,00$ a $\mathrm{R} \$ 8.700,00-27,3 \%$ \\
\hline & $>56$ anos $-15,1 \%$ & $\mathrm{R} \$ 8.701,00$ a $\mathrm{R} \$ 20.300,00-48,5 \%$ \\
\hline Cargo Ocupado & Escolaridade & Tempo de atuação \\
\hline Técnico bancário - 30,3\% & Ensino médio - 3\% & De 1 a 5 anos $-21,2 \%$ \\
\hline Caixa - 3\% & Superior Incomp. - 15,2\% & De 6 a 10 anos $-12,2 \%$ \\
\hline Tesoureiro - 6,1\% & Ensino Superior - 54,6\% & De 11 a vinte anos $-33,3 \%$ \\
\hline Assistente - 21,2\% & Pós-graduação - 24,2\% & Acima de 20 anos $-33,3 \%$ \\
\hline Supervisor $-6,1 \%$ & Mestrado - 3\% & \\
\hline \multicolumn{3}{|l|}{ Gerente - 21,2\% } \\
\hline Outros - 12,1\% & & \\
\hline
\end{tabular}


Tabela 2. Perfil geral bancos particulares.

\begin{tabular}{lll}
\hline Sexo & Faixa Etária & Renda Familiar \\
\hline Feminino $-41,7 \%$ & 18 a 25 anos $-16,6 \%$ & $\mathrm{R} \$ 1.451,00$ a $\mathrm{R} \$ 2.410,00-5,6 \%$ \\
Masculino $-55,5 \%$ & 26 a 35 anos $-50 \%$ & $\mathrm{R} \$ 2.411,00$ a $\mathrm{R} \$ 4.430,00-33,3 \%$ \\
Não respondeu $-2,8 \%$ & 36 a 45 anos $-16,6 \%$ & $\mathrm{R} \$ 4.431,00$ a $\mathrm{R} \$ 8.700,00-38,9 \%$ \\
& 46 a 55 anos $-11,1 \%$ & $\mathrm{R} \$ 8.701,00$ a $\mathrm{R} \$ 20.300,00-22,2 \%$ \\
& $>56$ anos $-2,7 \%$ & \\
\hline Cargo 0cupado & Não respondeu $-3 \%$ & \\
\hline Caixa $-16,7 \%$ & Escolaridade & Tempo de atuação \\
Assistente $-11,1 \%$ & Ensino médio $-2,8 \%$ & Até 1 ano $-2,8 \%$ \\
Supervisor $-13,9 \%$ & Superior Incomp. $-16,7 \%$ & De 1 a 5 anos $-30,6 \%$ \\
Gerente $-47,2 \%$ & Ensino Superior $-55,5 \%$ & De 6 a 10 anos $-27,8 \%$ \\
Outros $-11,1 \%$ & Pós-graduação $-11,1 \%$ & De 11 a vinte anos $-19,4 \%$ \\
\hline
\end{tabular}

Nas instituições públicas, prevaleceu entre os respondentes 0 gênero masculino, com faixa etária de 26 a 35 anos, renda familiar predominante de $R \$ 8.700$ a $R \$ 20.300$, cargo técnico bancário, com ensino superior completo e mais de 20 anos de atuação na instituição. Nos bancos particulares, o perfil também é formado com a maioria pertencente ao gênero masculino, com faixa etária predominante entre 26 a 35 anos, renda familiar de maior frequência na faixa de $R \$ 4.400$ a $R \$ 8.700$, cargo gerencial, ensino superior completo e o tempo de atuação entre 1 e 5 anos de trabalho na empresa. A comparação entre os perfis mostrou que os colaboradores das instituições privadas em relação à públicas são mais jovens, com renda familiar mais baixa $\mathrm{e}$ trabalham há menos tempo na empresa.

Sobre os indicadores de postura responsável, na tabela 3 , verificou-se que os colaboradores sabem da existência de uma política formal $(87,9 \%$ nas IF públicas e $88,9 \%$ nas IF privadas), mas estes colaboradores têm dúvidas se todos os seus colegas conhecem estas diretrizes. Além disso, as respostas mostraram que os colaboradores conhecem parcialmente o aparelhamento e ações do banco em relação a cuidados com o meio ambiente, traduzidos pela presença nas unidades de coleta seletiva, mecanismos de racionamento do uso de água, procedimentos que reduzem o consumo de materiais de insumo, além de programas de reciclagem de papel.

Entretanto, a avaliação dos colaboradores aponta que os dois tipos de instituições têm a preocupação em respeitar o meio ambiente, além de abordarem de alguma forma a preservação ambiental em sua missão, sua visão e seus valores. Este resultado corrobora os achados de Parente et al. (2013) e Nalesso et al. (2013), que identificaram que os colaboradores não conhecem muito bem o trabalho feito pelas instituições na área socioambiental.

Com relação à percepção sobre a postura responsável das instituições (tabela 4), ou seja, aquilo que de fato os bancos fazem sobre o assunto, constatouse que, de forma geral, os colaboradores das duas instituições detectam a existência de uma política ambiental formal no banco e que consta no código de conduta ou nos valores da organização, além da preocupação que o banco apresenta com a preservação do meio ambiente. 
Tabela 3. Indicadores da postura responsável ambientalmente das instituições financeiras.

\begin{tabular}{l|c|c|c|c|c|c|c|c}
\hline Alternativas de respostas: Sim x Não & \multicolumn{3}{|c|}{ Instituição Pública } & \multicolumn{3}{|c}{ Instituição Privada } \\
\hline \multicolumn{1}{c|}{$\mathbf{N}=\mathbf{6 9}$} & Sim & $\mathbf{\%}$ & $\mathbf{N a ̃ o}$ & $\mathbf{\%}$ & Sim & $\mathbf{\%}$ & $\mathbf{N a ̃ o}$ & $\%$ \\
\hline $\begin{array}{l}\text { 1. O banco possui uma política ambiental } \\
\text { formal? }\end{array}$ & 29 & 87,9 & 4 & 12,1 & 32 & 88,9 & 4 & 11,1 \\
\hline $\begin{array}{l}\text { 2. Essa política é de conhecimento de todos os } \\
\text { servidores? }\end{array}$ & 14 & 42,4 & 19 & 57,6 & 23 & 63,9 & 13 & 36,1 \\
\hline $\begin{array}{l}\text { 3. Ela consta no código de conduta ou nos } \\
\text { valores da organização? }\end{array}$ & 26 & 78,8 & 7 & 21,2 & 28 & 77,8 & 8 & 22,2 \\
\hline $\begin{array}{l}\text { 4. O banco possui lixeiras próprias para coleta } \\
\text { seletiva? }\end{array}$ & 11 & 33,3 & 22 & 66,7 & 12 & 33,3 & 24 & 66,7 \\
\hline $\begin{array}{l}\text { 5. Possui torneiras e/ou descargas com } \\
\text { mecanismo de racionalização no uso de água? }\end{array}$ & 14 & 42,4 & 19 & 57,6 & 18 & 50 & 18 & 50 \\
\hline $\begin{array}{l}\text { 6. Existe alguma tecnologia/ação que minimize } \\
\text { a entrada de materiais de insumo no banco? }\end{array}$ & 11 & 33,3 & 22 & 66,7 & 12 & 33,3 & 24 & 66,7 \\
\hline $\begin{array}{l}\text { 7. O banco possui programas de reciclagem de } \\
\text { papel? }\end{array}$ & 19 & 57,6 & 14 & 42,4 & 15 & 41,7 & 21 & 58,3 \\
\hline
\end{tabular}

Tabela 4. Percepção dos funcionários sobre a postura responsável ambientalmente das instituições financeiras.

\begin{tabular}{|c|c|c|c|c|c|c|}
\hline $\begin{array}{l}\text { Escala: 1- Nunca, 2- Raramente, 3- Às vezes, 4- } \\
\text { Frequentemente, 5- Sempre. }\end{array}$ & $\mathbf{N}$ & $\begin{array}{l}\text { Média } \\
\text { Geral }\end{array}$ & $\begin{array}{l}\text { Desvio } \\
\text { Padrão }\end{array}$ & $\begin{array}{l}\text { Média } \\
\text { Pública }\end{array}$ & $\begin{array}{c}\text { Média } \\
\text { Particular }\end{array}$ & $\begin{array}{l}\text { Teste t } \\
\text { (p) }\end{array}$ \\
\hline $\begin{array}{l}80 \text { banco tem a preocupação em respeitar o } \\
\text { meio ambiente? }\end{array}$ & 69 & 4,08 & 0,81 & 3,94 & 4,22 & 0,15 \\
\hline $\begin{array}{l}9 \text { A missão, a visão e os valores do banco } \\
\text { abordam de alguma forma a preservação } \\
\text { ambiental do planeta? }\end{array}$ & 69 & 3,94 & 0,90 & 3,90 & 3,97 & 0,77 \\
\hline $\begin{array}{l}10.0 \text { banco possui alguma política que visa à } \\
\text { reutilização de insumos? }\end{array}$ & 69 & 2,98 & 1,23 & 2,96 & 3,00 & 0,92 \\
\hline $\begin{array}{l}\text { 11. O banco disponibiliza informações como } \\
\text { políticas internas de preservação ambiental e } \\
\text { treina os colaboradores para que possam } \\
\text { compreendê-las e aplicá-las? }\end{array}$ & 69 & 3,10 & 1,10 & 3,03 & 3,16 & 0,61 \\
\hline $\begin{array}{l}\text { 12. } 0 \text { banco promove palestras ou seminários } \\
\text { que incentivam a conscientização ambiental de } \\
\text { seus colaboradores? }\end{array}$ & 69 & 2,63 & 1,04 & 2,57 & 2,69 & 0,64 \\
\hline $\begin{array}{l}\text { 13. } 0 \text { banco tem a preocupação em difundir e } \\
\text { incentivar os colaboradores a adotarem práticas } \\
\text { de preservação da natureza? }\end{array}$ & 69 & 3,28 & 1,09 & 3,18 & 3,38 & 0,43 \\
\hline $\begin{array}{l}\text { 14. O banco possui mecanismos formais para } \\
\text { ouvir, avaliar e acompanhar sugestões e críticas } \\
\text { dos colaboradores com o objetivo de agregar } \\
\text { novos conhecimentos no aspecto ambiental? }\end{array}$ & 69 & 2,88 & 1,25 & 2,48 & 3,25 & 0,01 \\
\hline $\begin{array}{l}\text { 15. O Banco apoia e incentiva projetos } \\
\text { ambientais desenvolvidos pelos funcionários? }\end{array}$ & 69 & 3,00 & 1,13 & 2,69 & 3,27 & 0,03 \\
\hline $\begin{array}{l}\text { 16. } 0 \text { banco se preocupa com a coleta seletiva de } \\
\text { materiais? }\end{array}$ & 69 & 3,01 & 1,19 & 2,87 & 3,13 & 0,37 \\
\hline $\begin{array}{l}\text { 17. } 0 \text { banco se preocupa com o desperdício de } \\
\text { água e de energia elétrica em suas agências? }\end{array}$ & 69 & 3,88 & 1,10 & 3,42 & 4,30 & 0,00 \\
\hline $\begin{array}{l}\text { 18. } 0 \text { banco realiza gerenciamento do consumo } \\
\text { de energia? }\end{array}$ & 69 & 3,69 & 1,16 & 3,30 & 4,05 & 0,00 \\
\hline
\end{tabular}


Tabela 4. Continuação.

\begin{tabular}{|c|c|c|c|c|c|c|}
\hline $\begin{array}{l}\text { Escala: 1- Nunca, 2- Raramente, 3- Às vezes, 4- } \\
\text { Frequentemente, 5- Sempre. }\end{array}$ & $\mathbf{N}$ & $\begin{array}{l}\text { Média } \\
\text { Geral }\end{array}$ & $\begin{array}{l}\text { Desvio } \\
\text { Padrão }\end{array}$ & $\begin{array}{l}\text { Média } \\
\text { Pública }\end{array}$ & $\begin{array}{c}\text { Média } \\
\text { Particular }\end{array}$ & $\begin{array}{l}\text { Teste t } \\
\text { (p) }\end{array}$ \\
\hline $\begin{array}{l}19.0 \text { banco se preocupa em utilizar papel } \\
\text { reciclado em suas agências? }\end{array}$ & 69 & 2,84 & 1,23 & 2,54 & 3,11 & 0,05 \\
\hline $\begin{array}{l}20.0 \text { banco realiza gerenciamento de } \\
\text { impressão/quantidade de papel utilizado? }\end{array}$ & 69 & 3,63 & 1,41 & 3,18 & 4,05 & 0,00 \\
\hline $\begin{array}{l}21.0 \text { banco realiza a mensuração dos resultados } \\
\text { obtidos com algum tipo de programa e/ou } \\
\text { campanha de preservação ambiental? }\end{array}$ & 69 & 2,73 & 1,32 & 2,36 & 3,08 & 0,02 \\
\hline $\begin{array}{l}\text { 22. O banco expõe publicamente seus } \\
\text { compromissos ambientais por meio de material } \\
\text { institucional, pela internet/intranet, ou de } \\
\text { alguma outra forma? }\end{array}$ & 69 & 3,34 & 1,14 & 2,93 & 3,72 & 0,00 \\
\hline Valid N (listwise) & 69 & & & & & \\
\hline
\end{tabular}

No entanto, alguns aspectos negativos foram identificados. De um modo geral, os colaboradores não perceberam nitidamente interesse por parte das instituições (públicas e privadas) em promover eventos que ajudem a melhorar a consciência ambiental, fator que deve ser levado em consideração em virtude da pesquisa realizada por Freitas et al. (2012), que aborda a assunção de um papel relevante por parte desta Educação na mudança da realidade, através do preparo do indivíduo.

Sobre as ações práticas em prol do meio ambiente, as respostas se mostraram diferentes entre colaboradores de instituições públicas e privadas. Os pontos em que houve respostas distintas em termos estatísticos (teste $t$, $\mathrm{p} \leq$ 0,05) foram em relação a: mecanismos formais para ouvir críticas e sugestões do pessoal sobre o assunto, apoio a projetos ambientais desenvolvidos pelos colaboradores, ações para reduzir consumo de materiais, água e energia, ações sobre encaminhamento de lixo com coleta seletiva, exposição de compromissos ambientais e mensuração dos resultados com programas nesta área. Os colaboradores das instituições privadas tiveram percepção mais positiva em relação a estes temas quando comparados com aqueles das instituições públicas.
No que tange às atitudes dos próprios colaboradores sobre o meio ambiente (Tabela 5), observou-se que eles têm consciência do que é a sustentabilidade ambiental, preocupamse com a preservação do meio ambiente e procuram evitar desperdícios. Este ponto merece destaque tendo em vista que, conforme Santos e Souza (2013), colaboradores que valorizam práticas ambientalmente responsáveis tendem a desenvolver relação de confiança com a empresa em que trabalham. Ainda segundo estes autores, a atitude dos funcionários pode ser influenciada pela responsabilidade socioambiental, por meio do envolvimento destes com a organização, tornando-a impulsionadora de mudanças de atitudes de seus colaboradores, na medida em que se envolvem com suas práticas.

Entretanto, identificou-se pelas respostas um envolvimento moderadamente baixo dos colaboradores, uma vez que não se consideram coresponsáveis com o banco em relação a possíveis danos ao meio ambiente, e não procuram orientar os colegas de trabalho sobre preservação ambiental. Esta dicotomia entre conscientização sobre questões ambientais e baixa predisposição em se envolver com as atividades em si encontra respaldo na literatura (Vaccari et al., 2016; Costa Filho et al., 2017). 
Tabela 5. Atitudes dos funcionários das Instituições Financeiras frente às questões ambientais.

\begin{tabular}{|c|c|c|c|c|c|c|}
\hline $\begin{array}{l}\text { Proposições fornecidas: 1- Discordo totalmente, 2- } \\
\text { Discordo, 3-Indiferente, 4- Concordo, 5- Concordo } \\
\text { totalmente. }\end{array}$ & $\mathbf{N}$ & $\begin{array}{c}\text { Média } \\
\text { geral }\end{array}$ & $\begin{array}{l}\text { Desvio } \\
\text { Padrão }\end{array}$ & $\begin{array}{l}\text { Média } \\
\text { Pública }\end{array}$ & $\begin{array}{l}\text { Média } \\
\text { Part. }\end{array}$ & $\begin{array}{l}\text { Teste } \\
\text { T (p) }\end{array}$ \\
\hline 23. Sei o que é sustentabilidade ambiental. & 69 & 4,23 & 0,59 & 4,18 & 4,27 & 0,50 \\
\hline $\begin{array}{l}\text { 24. Acredito que o banco no qual trabalho é } \\
\text { responsável ambientalmente. }\end{array}$ & 69 & 3,88 & 0,73 & 3,69 & 4,05 & 0,04 \\
\hline $\begin{array}{l}\text { 25. Preocupo-me com a preservação do meio } \\
\text { ambiente. }\end{array}$ & 69 & 4,36 & 0,54 & 4,36 & 4,36 & 0,98 \\
\hline $\begin{array}{l}\text { 26. Executo profissionalmente, tarefas prejudiciais ao } \\
\text { meio ambiente. }\end{array}$ & 69 & 2,68 & 1,14 & 2,69 & 2,66 & 0,91 \\
\hline $\begin{array}{l}\text { 27. Acredito ser corresponsável pelos possíveis danos } \\
\text { ambientais causados pelo banco em que trabalho. }\end{array}$ & 69 & 3,05 & 1,16 & 3,12 & 3,00 & 0,66 \\
\hline 28. Evito desperdícios no ambiente de trabalho. & 69 & 4,17 & 0,70 & 4,06 & 4,27 & 0,20 \\
\hline $\begin{array}{l}\text { 29. Oriento outras pessoas para a preservação } \\
\text { ambiental no trabalho. }\end{array}$ & 69 & 3,59 & 1,01 & 3,36 & 3,80 & 0,07 \\
\hline $\begin{array}{l}\text { 30. Preocupo-me com a coleta seletiva de materiais } \\
\text { dentro do banco. }\end{array}$ & 69 & 3,53 & 1,09 & 3,36 & 3,69 & 0,21 \\
\hline Valid N (listwise) & 69 & & & & & \\
\hline
\end{tabular}

Sob o aspecto comportamental, o estudo analisa a diferença de comportamentos dentro das instituições e a postura de cada colaborador, por meio de suas ações, frente à responsabilidade socioambiental (Tabela 6).

Tabela 6. Comportamento apresentado pelos colaboradores das Instituições Financeiras frente à responsabilidade socioambiental.

\begin{tabular}{l|c|c|c|c|c|c}
\hline $\begin{array}{l}\text { Proposições fornecidas: 1- Nunca, 2- } \\
\text { Raramente, 3- Às vezes, 4- Frequentemente, 5- } \\
\text { Sempre. }\end{array}$ & $\mathbf{N}$ & $\begin{array}{c}\text { Média } \\
\text { Geral }\end{array}$ & $\begin{array}{c}\text { Desvio } \\
\text { Padrão }\end{array}$ & $\begin{array}{c}\text { Média } \\
\text { Pública }\end{array}$ & $\begin{array}{c}\text { Média } \\
\text { Particula } \\
\text { r }\end{array}$ & $\begin{array}{c}\text { Teste T } \\
\text { (p) }\end{array}$ \\
\hline $\begin{array}{l}\text { 31. Você reutiliza papel impresso em apenas um } \\
\text { dos lados na execução de suas atividades? }\end{array}$ & 69 & 3,33 & 1,22 & 3,21 & 3,44 & 0,43 \\
\hline $\begin{array}{l}\text { 32. Você configura sua impressora para a } \\
\text { impressão de frente e verso na folha? }\end{array}$ & 69 & 4,15 & 1,15 & 4,27 & 4,05 & 0,44 \\
\hline $\begin{array}{l}\text { 33. Você desliga seu computador após o } \\
\text { expediente? }\end{array}$ & 69 & 4,63 & 0,87 & 4,72 & 4,55 & 0,41 \\
\hline $\begin{array}{l}\text { 34. Você desliga o monitor do computador de } \\
\text { trabalho quando o mesmo não está em uso? }\end{array}$ & 69 & 3,79 & 1,44 & 4,00 & 3,61 & 0,26 \\
\hline $\begin{array}{l}\text { 35. Você desliga as luzes ao sair de um ambiente } \\
\text { do banco em que não haja outras pessoas? }\end{array}$ & 69 & 4,36 & 1,05 & 4,06 & 4,63 & $\mathbf{0 , 0 2}$ \\
\hline $\begin{array}{l}\text { 36. Você aproveita a iluminação natural dos } \\
\text { ambientes na instituição? }\end{array}$ & 69 & 3,13 & 1,40 & 2,69 & 3,52 & $\mathbf{0 , 0 1}$ \\
\hline $\begin{array}{l}\text { 37. Você evita o desperdício de água nas } \\
\text { dependências do banco? }\end{array}$ & 69 & 4,36 & 0,87 & 4,09 & 4,61 & $\mathbf{0 , 0 1}$ \\
\hline $\begin{array}{l}\text { 38. Você separa o seu lixo orgânico do lixo } \\
\text { reciclável em seu ambiente de trabalho? }\end{array}$ & 69 & 2,81 & 1,38 & 2,75 & 2,86 & 0,75 \\
\hline $\begin{array}{l}\text { 39. Você faz uso consciente do material de } \\
\text { expediente? }\end{array}$ & 69 & 4,21 & 0,82 & 4,15 & 4,27 & 0,52 \\
\hline $\begin{array}{l}\text { 40. Você contribui com sugestões que possam } \\
\text { melhorar o desempenho ambiental do banco? }\end{array}$ & 69 & 2,84 & 1,31 & 2,48 & 3,16 & $\mathbf{0 , 0 3}$ \\
\hline \begin{tabular}{l} 
Valid N (listwise) \\
\hline
\end{tabular} & 69 & & & & & \\
\hline
\end{tabular}


Admitindo que se for efetivada uma avaliação positiva acerca da responsabilidade socioambiental, colaboradores tendem a empregar comportamentos favoráveis a esta causa, principalmente na execução de suas tarefas diárias.

De um modo geral, os colaboradores já incorporaram em seu dia-a-dia certa ações consideradas ambientalmente corretas. As respostas mostraram que eles fazem uso consciente do material de expediente, incluindo redução no consumo de papel de impressoras, ainda muito utilizadas em bancos; desligam luzes e equipamentos ao final do dia de trabalho; evitam desperdício de água nas dependências do banco. Entretanto, ainda poderiam melhorar nos seguintes aspectos: realizar coleta seletiva, separando lixo orgânico do lixo reciclável, fazer aproveitamento da iluminação natural, racionando 0 consumo de energia; maximizar o uso de papéis de impressão, utilizando ambos os lados sempre que possível. Além disso, seria interessante que os colaboradores pudessem contribuir com sugestões de melhoria, o que aumenta o envolvimento e comprometimento com os resultados das ações ambientais. Vale lembrar que conforme Santos e Souza (2013), colaboradores que valorizam práticas ambientalmente responsáveis, são mais propensos a desenvolver relação de confiança com a empresa.

Quando comparadas instituições públicas e privadas, o banco particular apresenta melhor comportamento no que tange o consumo de água e energia elétrica em suas dependências, traduzidos em custos para a unidade de atuação de cada colaborador, delineando uma conotação ambiental e econômica nestes fatores. Além disso, o banco particular ainda recebe maiores contribuições por meio de sugestões de seus empregados.

As análises mostraram que em termos de percepções, atitudes e comportamentos, os colaboradores apresentaram certo grau de conhecimento, predisposição favorável e comportamentos consistentes em prol do meio ambiente. No entanto, a leitura detida das respostas revelou que ainda há espaço para maior envolvimento e desenvolvimento de ações proativas por parte destes colaboradores. Neste sentido, é muito importante o papel das instituições com programas de educação ambiental, o que tem considerável poder de influência positiva em relação ao seu pessoal (Araujo et al., 2014). A empresa deve evitar a ocorrência do fenômeno greenwashing, ou seja, envidar ações somente para mostrar que se é ecologicamente correto (Silva e Lopes, 2014).

\section{Conclusões}

Um ímpeto por mudanças com relação à preservação ambiental do planeta deu origem ao presente estudo sobre Responsabilidade Social Corporativa no contexto bancário, após a percepção da carência de análises nesse setor.

O acompanhamento da percepção de políticas socioambientais implementadas dentro das instituições financeiras em estudo e a comparação entre comportamentos na execução das atividades diárias, revelou que as agências bancárias de instituições privadas se apresentam mais próximas de um resultado positivo no âmbito de uma postura ambientalmente correta.

Há ferramentas disponíveis para uma atuação consciente na execução das rotinas exigidas, recaindo sobre as Instituições a responsabilidade de aprimorarem seus programas e envolverem em maior grau seus colaboradores, visto que os resultados ressaltam uma consciência ambiental em formação no público entrevistado.

Tanto o nível de conhecimento quanto a percepção que os funcionários apresentaram da instituição no aspecto 
da Responsabilidade Social Ambiental, foram satisfatórios, com possibilidade de melhores performances.

No comparativo entre os dois perfis institucionais pesquisados, a instituição financeira privada se mostrou, de forma geral, com melhores resultados, desde a percepção até o comportamento.

0 estudo respondeu ao objetivo inicial do trabalho, apesar da percepção de que os maiores limitadores da pesquisa foram fatores externos de difícil acesso. Dentre eles, destacam-se o desinteresse em responder pesquisas científicas por parte do público alvo; a indiferença existente ao tema abordado; a possível falta de compromisso com a veracidade das respostas; e, principalmente, a crença de que a pesquisa não agregará resultados ao cotidiano bancário.

Todavia, a elaboração deste, despertou outras questões que podem ser contempladas em estudos futuros: os programas instituídos nas Instituições bancárias, quais são eles, como eles funcionam, quais suas abrangências; a influência que a conduta ambiental de colaboradores pode exercer na prospecção e retenção de clientes; e o levantamento do impacto ambiental que as atividades bancárias causam.

\section{Conflito de interesses}

Os autores declaram não haver conflito de interesses.

\section{Referências}

Andrade, T.; Costa, V. F.; Estivalete, V. F. B.; Lengler, L. Valores do trabalho e satisfação como antecedentes dos comportamentos de cidadania organizacional: um estudo com colaboradores do setor educacional. Anais do XXXIX Encontro da ANPAD, Belo Horizonte, p. $1-16,2015$.

Araújo, A. A.; Bezerra, T. M. P.; Carpio, H. S. U. D.; Santos, S. N. N.; França, P. A. R.; Guimarães, M. G. V. O sistema de gestão ambiental como impulsor da educação ambiental: um estudo de caso em uma empresa do pólo industrial de Manaus (PIM) a partir da percepção de seus colaboradores. Revista Monografias Ambientais - REMOA, $\begin{array}{lll}\text { v. } 13, & \text { n. } 4, \quad \text { p. } 3580-3590, & 2014 .\end{array}$ https://doi.org/10.5902/2236130814169

Bagnolo, C. M. Empresariado e ambiente: algumas considerações sobre a educação ambiental no espaço escolar. Ciência \& Educação, v. 16, n. 2, p. 401-413, 2010. https://doi.org/10.1590/S1516-73132010 000200009

Beuron, T. A.; Madruga, L. R. R. G.; Ávila, L. V.; Galvão, F. F.; Schuch Jr., V. F. Uma análise dos valores organizacionais sob a perspectiva da sustentabilidade: contribuições a partir da percepção dos empregados. Revista Gestão e Sustentabilidade Ambiental, v. 3, n. 1, p. 165-184, 2014. https://doi.org/10.19177/ rgsa.v3e12014165-184

Blank, D. M.P.; Brauner, M. C. C. A responsabilidade civil ambiental das instituições bancárias pelo risco ambiental produzido por empresas financiadas. REMEA - Revista Eletrônica do Mestrado em Educação Ambiental, v. 22, p. 261-275, 2009.

Braga, C. O. S.; Moura, A. S. S. Protocolo Verde: a realidade da sustentabilidade ambiental nas instituições financeiras no Brasil. Anais da VII Jornada Internacional Políticas Públicas, São Luiz, Maranhão, 2016.

Brandalise, L. T.; Bertolini, G. R. F. Instrumentos de medição de percepção e comportamento: uma revisão. Revista Ciências Empresariais, v. 14, n. 1, p. 7-34, 2013.

Campos, A.; Ardisson, D. P. Por uma nova concepção jurídica de empresa no Marco da Sociedade do Risco: do lucro inconsequente à responsabilidade socioambiental. Sequência, n. 64 , p. 85-104, 2012. https://doi.org/ 10.5007/2177-7055.2012v33n64p85

CMMAD - Comissão Mundial Sobre Meio Ambiente e Desenvolvimento. Nosso futuro comum. 2. ed. Rio de Janeiro: Fundação Getúlio Vargas, 1991.

Costa Filho, B. A.; Rosa, F.; Coelho, M. F. Consumer environmental concern: The imbalance between values, attitudes and behaviour - a survey in Central Brazil. International Journal of Environment and Sustainable Development, v. 16, n. 3, 
p. 279-296, 2017. https://doi.org/10.1504/ IJESD.2017.085070

Cruvinel, E. Responsabilidade social em instituições financeiras: a institucionalização da prática nos bancos no Brasil. Rio de Janeiro: Elsevier, 2008.

Feitosa, M. J. S.; Souza, N. M. O.; Santos, R. S.; Firmo, L. A. Estágio de desenvolvimento da responsabilidade social empresarial no setor bancário: um estudo em uma Agência do Banco do Brasil. Revista Metropolitana de Sustentabilidade - RMS, v. 4, n. 3, p. 15-27, 2014.

Garcia, K. C.; Teixeira, M. G.; Alves, C. C.; Alves, R. N. Concepção de um modelo matemático de avaliação de projetos de responsabilidade social empresarial (RSE). Gestão \& Produção, v. 14, n. 3, p. 535-544, 2007. https://doi.org/10.1590/S0104-530X 2007000300009

Ipiranga, A. S. R.; Godoy, A. S.; Brunstein, J. Introdução. RAM. Revista de Administração Mackenzie, v. 12, n. 3, p. 1320, 2011. https://doi.org/10.1590/S167869712011000300002

Kelm, M. L.; Renz, C. L. S.; Allebrandt, S. L.; Sausen, J. O. Institucionalização das iniciativas socioambientais das organizações: interfaces entre a teoria do desenvolvimento social de Habermas e o isomorfismo da teoria institucional. Cadernos EBAPE.BR, v. 12, Edição Especial, p. 401-415, 2014. https://doi.org/10.1590/1679-39519097

Likert, R. A technique for the measurement of attitudes. Archives of Psychology, v. 22, n. 140, p. 1-55, 1932.

Medeiros, M. S.; Barbosa, R. F.; Sousa, J. E.; Alexandre, S. N.; Oliveira, C. G. S. B. Gestão ambiental e sustentabilidade: um estudo de caso na agência do Banco do Brasil de Alagoa Nova/PB. Revista Eletrônica em Gestão, Educação e Tecnologia Ambiental, v. 19, n. 3, p. 256-273, 2015.

Nalesso, A. C.; Stipp, D. M.; Ramos, M. V. O.; Souza-de-Godói, E. Responsabilidade socioambiental: valor ou artefato da cultura? Análise da percepção dos colaboradores empresariais. Anais do IV Encontro de Gestão de Pessoas e Relações de Trabalho, Brasília, p. 1-3, 2013.
Parente, T. C.; Penha, E. D. S.; Fischer, A. L. Empresas socialmente responsáveis são reconhecidas como tais pelos seus colaboradores? Anais do XXXVII Encontro da ANPAD, p. 1-16, 2013.

Rodrigues, J. D.; Moreira, V. F.; Oliveira, A. M. B.; Aguiar, E. C.; Barbosa, O. T. Comportamento de consumo verde: uma análise dos consumidores de Campina Grande. Revista Brasileira de Administração Científica, v. 5, n. 1, p. 316332, 2014. https://doi.org/10.6008/ SPC2179-684X.2014.001.0019

Rufino, M. A.; Mazer, L. P.; Machado, M. R.; Cavalcante, P. R. N. Sustentabilidade e performance dos indicadores de rentabilidade e lucratividade: um estudo comparativo entre os bancos integrantes e não integrantes do ISE da BM\&FBOVESPA. Revista Ambiente Contábil, v. 6, n. 1, p. 1-18, 2014.

Santos, F. P.; Souza, L. B. Estudo da percepção da qualidade ambiental por meio do método fenomenológico. Mercator, v. 14, n. 2, p. 5774, 2015. https://doi.org/10.4215/RM2015. 1402.0004

Santos, J. G.; Souza, N. M. O. A Influência da responsabilidade empresarial no comprometimento dos colaboradores: uma compreensão à luz da Teoria do Comportamento Planejado. Anais do IV Encontro de Gestão de Pessoas e Relações de Trabalho, Brasília, p. 1-16, 2013.

Santos, P. M. F.; Porto, R. B. Responsabilidade ambiental e lealdade de clientes em banco de varejo. Revista de Administração de Empresas, v. 54, n. 6, p. 606-618, 2014. https://doi.org/10.1590/S0034-75902014 0602

Silva, A. M. M.; Lopes, W. G. R. Virtude e falácias do marketing verde e consumo sustentável: a percepção de servidores públicos de instituições de ensino em Teresina, Piauí. REDE - Revista Eletrônica do PRODEMA, v. 8, n. 2, p. 77-91, 2014.

Silva, I. P.; Veloso, M. N.; Barroso, J. A.; Pinto, L. A.; Torres, E. F. Consciência ambiental versus as práticas de comportamento próambiental de acadêmicos de graduação. Revista Eletrônica de Gestão Organizacional, v. 14, Edição Especial, p. 5974, 2016 . 
Tamashiro, H. R. S.; Murari, W. A.; Oliveira, S. V. W. B.; Acevedo, C. R. Comportamento socioambiental do consumidor: um estudo com universitários do interior paulista. Produção, v. 22, n. 2, p. 201-212, 2012. https://doi.org/10.1590/S0103-6513 2012005000011

Vaccari, L. C.; Cohen, M.; Rocha, A. M. C. 0 hiato entre atitude e comportamento ecologicamente conscientes: um estudo com consumidores de diferentes gerações para produtos orgânicos. Revista Eletrônica de Gestão Organizacional, v. 14, Edição Especial, p. 44-58, 2016.

Véras, M. L. Avaliação do estágio de desenvolvimento da responsabilidade social no Banco Central do Brasil. Rio de Janeiro: Fundação Getúlio Vargas, Escola Brasileira de Administração Pública, 2009. (Dissertação de mestrado). seja devidamente citada. 